\title{
VISUAL INTEGRATION OF GEODATA IN THEMATIC CARTOGRAPHY
}

DOI: http://dx.doi.org/10.18509/GBP.2019.81

UDC: UDK 528.93:[528.85:004.9

\author{
Jasmina M. Jovanović ${ }^{1}$, \\ Vladan Grbović1, \\ Svemir Gorin ${ }^{2}$ \\ ${ }^{1}$ University of Belgrade - Faculty of Geography, Belgrade, Studentski trg 3/III, Serbia \\ ${ }^{2}$ Institute of Geography, Faculty of Natural Sciences and Mathematics, \\ Ss. Cyril and Methodius University, Skopje, Macedonia
}

\begin{abstract}
Contemporary cartographic production requires working with databases, of various topographic and thematic structures, which must be standardized and with the possibility of converting values from one data type to another. In order to better map out the reality, in the modeling process, the geodata are systematized within the databases, graphically integrated in regard to thematic significance (primary and secondary). Cartographic methods of geo-visualization offer numerous solutions for interactive visual representation of thematic content. Adjusting the graphic representation and ways of interaction while using the cartographic models allow the visualization of the "hidden" content provided by geodata. By integrating standardized data, in the framework of a database (classification, standardization ...), besides the basic cartographic representation, the interconnected and conditioned additional and supplementary, synchronized graphical representations of the cartographic issues can be realized. Synchronized representations can originate from the same database as the basic map or they can be made by combining data from multiple different databases (with the ability to manipulate within the same formats, classifications, standardizations ...). In doing so, the interactive capabilities in manipulating the maps must be well thought out and evaluated. The approach, ways and limits of database manipulation, as well as the offered cartographic visualization solutions, should provide users with highlighting of the most important aspects of the representation. The coordination of different, but synchronized representations is enabled by visual integration of geodata, in order to create a geo-visual environment in the context of understanding large amounts of data (content, space and time). A complex structure of geodata can be cartographically integrated and presented if it is adapted and based on the principles of cartographic generalization and cartographic design. The content generalization on a model can be the following: taxonomical, spatial, attributive and graphical. The content generalization and symbolization of the thematic maps are key procedures for geo-visualization. The degree of generalization (geometric and semantic) influences the degree of data integration that are graphically represented.
\end{abstract}

Key words: Thematic map, geo-visualization, integration, geodata, generalization

\section{INTRODUCTION}

The development of information and communication technologies (ICT) has influenced the increasing importance of cartography, especially the thematic one, in realization of numerous human activities, from local to global level. Digital production and the wide 
field of application of thematic maps have influenced the complexity of the approach in compiling the contents of thematic maps. Complexity arises from the context of the representation of the characteristics of phenomena and the process of geoenvironment, the defined selection of geodata and the ways of cartographic visualization. Maps are the most compact and the simplest way to represent geographic information, and digital technology enables the application of modern forms of database visualization. A digital map, as a representation of a large set of integrated geodata, provides a visual interactive approach to the analysis and comparison of the geoenvironmental content components, which is the subject of research and understanding. In doing so, it is necessary that the interactive capabilities in map manipulation are well thought out and evaluated. The approach, ways and limits of database manipulation, as well as the offered solutions for cartographic visualization to users, should ensure the highlighting of the most important aspects of the representation of the geoenvironmental content components.

\section{CARTOGRAPHIC VISUALIZATION OF GEODATA}

The digital technique provides great opportunities for modern cartographic visualization, preceded by increasing demands that the plurality of data, which in real time exist from different sources, is represented in a comprehensible way in their dynamics of movement and changes to a large number of users. The quality of data and the way of their presentation on the map define the quality of obtaining information. Securing informatics by cartographic visualization of geoenvironmental content must satisfy scientific credibility, spatial and contextual integrity, adequate degree of detail, functional and aesthetical originality and optimal sphere of application [7].

Cartographic visualization of geoenvironmental content components, using the mapping methods (modeling and interpretation), enables obtaining graphical and numerical information on real and abstract phenomena and geoenvironmental processes for different scientific and practical needs. The process implementation of the cartographic method enables the system of applied methods. Cartographic modeling involves the application of the following: - mathematical-cartographical and - concrete cartographical methods (relief presentation methods and mapping methods), as well as - constructional methods (content constructing methods), and the process of cartographic interpretation includes application - of the concrete cartometric methods (morphometry, semiometry and other) [6]. Digital technology has expanded geodata visualization capabilities and in that way enhanced the information value of cartographic models. That is, a visual integral presentation of knowledge about geoenvironment, using modern techniques, results in the creation of an effective model that simulates reality (concrete and abstract).

Characteristics of reality in a simplified, graphic form allow for a faster and better interpretation of reality. The map interprets the meaning of a large number of data, clearly and transparently, to a large number of users of different educational levels. The development of ICT has influenced the popularization of maps, especially the thematic ones. More and more animated and interactive maps, 3D and 4D presentations are used in various areas of human activity. Transformation of complex data into a visually simple picture of reality and the possibility of visual searching, finding and interpreting the desired data, making decisions, etc., have contributed to the great interest for using maps in everyday life of people.

The ability of visual information presentation about geographic phenomena and processes is one of the most important advantages of geographic information systems. A long and complicated process of studying tables, charts, textual data by map replacement becomes 
clearer. Therefore, the use of maps, especially the thematic ones, is of great importance. Geographic Information Systems (GIS) have given impetus to the further development of thematic maps. In order to show the results of data analysis in GIS, the methods used in creating thematic maps are implemented, but new visual tools and techniques are introduced as well. With the help of GIS, the process of creating thematic maps, as well as their availability to a large number of users, becomes faster and easier.

In the visualization of geodata, a cartographic method is chosen that interprets the phenomena and processes of geoenvironment in the most expedient way. In order to better present the cartographic reality, the data are graphically integrated in regard to the thematic significance. By using characters and colours, the message is transmitted most efficiently. The data must be carefully selected in the context of mapping issues, accurate, standardized, adapted to the extent and structure of the mapping issues, in order to provide, after cartographic visualization, in addition to analysis and comparison, the synthesis of information on the researched area.

The use of software tools for digital representation of geodata must be oriented to cartographic presentation rules. The goal is to create as realistic model as possible on the basis of which it is possible to obtain relevant information by visualizing. Mapping allows visual identification of the contextual, structural and functional characteristics of natural and social phenomena and processes, in order to study their interrelations and relationships. The procedure includes the following:

- collecting and processing a large number of data, within the various scientific and professional fields;

- graphically accurate, precise, integrated, professionally and aesthetically integrated presentation of data, with an adequate degree of generalization and

- application of an adequate, thematically adjusted cartographic method and cartographic expression means [8].

In order to effectively obtain information about the researched components of the geoenvironmental content, the process of cartographic visualization should be characterized by: - spatial and - temporal explicitity, - contextual conciseness, - graphical simplicity, - attractiveness and - credibility, - interaction with defined degree of manipulation of the thematical structure parameters, controlled possibility of transformation into other formats, - practical importance and - verification in practice.

\section{CARTOGRAPHIC PRODUCTION AND GIS}

The nature of maps and their use in science and in society in general are adapted to changes, stimulated by current and forecasted scientific and social needs for georeferenced information. The rapid development of technology enables innovative approaches to obtaining a wide range of information. The concept of visualization is in the basis of such changes. Visualization, in terms of creating the notion of the world, has always been an integral part of cartography [13].

The increasing importance of GIS has also affected the significance and scale of cartographic production in a scientific and practical view. Contemporary cartographic production requires working with databases, of various topographic and thematic structures which must be standardized and with the possibility of converting values from one data type to another in order to be visualized. The database structure includes a wide range of physical-geographical and socio-geographical themes. In order to better map out the reality, the geodata systematized within the databases are graphically integrated with respect to thematic significance (primary or secondary) for the purpose of transformation 
for further processing and use. A high-quality cartographic representation requires the database structure to be: - geometrically and attributively uniform, - standardized and integrated, - spatially homogeneous, - temporally compliant, - reliable, - current and adapted to use. In addition to the application of modern computer technology, the database visualization requires knowledge and use of methodological rules of conventional thematic cartography.

Integration of geodata (location and attribute) rationalizes and increases user-driven analytic potential. By integrating standardized data within the database (classification, typization ...), in addition to the basic cartographic representation, the interlinked and conditioned additional and supplementary, synchronized representations of the cartographic issues can be realized. Synchronized representations can originate from the same database as the basic map or made by combining data from multiple different databases (with the ability to manipulate within the same formats, classification, typizations ...). Visual geodata integration enables the coordination of different representations. In addition to the basic, additional and supplementary maps, visual representations can also include diagrams, charts, tables, text, and images. All this in order to create a geo-visual environment, and in the context of understanding a large amount of data. By adapting the graphic representation and ways of geodata interaction, in the use of cartographic models, the visualization of "hidden" thematic contents is possible. Interaction is the basic mechanism that allows users to "move" through the representation, search, filter and compare different sources of geographic data [1], [10], [11].

In order to show the results of data analysis in GIS, it is necessary to implement the methods used in creating thematic maps. Cartographic ways of representations of data analysis results can be supplemented by different contents. Tables and charts that include different characteristics of geoobjects (attributes) or their correlations can be used as independent or additional/supplementary visualization content. Animations are used to represent dynamic processes - sequences, creating an illusion of continuous image change. Virtual 3D and 4D models can be represented in the form of a static image or in interactive visualization. For example, using a different projection or viewing angle, images can be rotated, simulated over the terrain, when the observer is at a point that is in accordance with the given coordinates, and so on. Animation of virtual 3D and 4D models allows for a realistic video representation to simulate the existing state and predict different scenarios of their development [14]. Visual dynamic representation of geodata and the production of 3D and 4D models are constantly increasing, as the application in different fields of science and practice is increasingly evolving.

In addition to data standardization and integration, as a prerequisite for the creation of high quality georepresentation, updating of the database is also necessary. Updating the data (location, attribute, and time) causes a smaller chance of failure in the full representation of complex events - spatially and temporally. The potentials of digital models and their usability for different types of research determines the permissible degree of manipulation of their parameters. In a geographical context, changes in geoenvironmental databases refer not only to changes in location or by attributes, but also include dynamic processes over time (same or different time intervals, cycles) [2]. 


\section{TRANSFORMATION OF INTEGRATED GEODATA IN THE PROCESS OF CARTOGRAPHIC COMMUNICATION}

Map is a model of reality (geographic space), and a cartographic method - a method of realizing a modeled reality. The transfer of information from real to modeled georepresentations is basically conditioned by research orientations. With customized variants of georepresentations and various solutions for data transformation from the same or different set, numerous animations and virtual models enable examination of the possible aspects of the situation and future scenarios of importance in the oriented scientific and/or practical geoenvironmental research. By interactive transformation of geodata and their visual presentation, through the map, a better interpretation of the research area (content, space and time) is achieved. Interaction affects the mapping process - data are determined, the importance of certain data is emphasized, the method of visual representation is selected... So, the process of interaction by digital maps can affect the quality of geographic reality perception.

The primary data of the geoenvironment from the database are integrated and transformed by geo-visualization into cartographic environment, so that interpretation and analysis can be managed by the use of modeled data. Use of the map provides the following: primary information, obtained by content analysis (by reading, understanding and measuring); - secondary information generated after the processing of the primary ones

(the result of a derived, synthetic interpretation) and - tertiary information, used for further, purpose-oriented research purposes.

The transformation of integrated geodata in the cartographic communication process comprises (basically) three phases:

- first phase - interpretation of the map content, defined primarily by the way of content visualization, educational level and user skills;

- second phase - conversion of primary information into information on derivatives, using cartometric methods and

- third phase - interpretation (analysis, comparison) of primary and secondary information, including the visual-analytical system of conclusions and new approaches to data visualization for further research.

Visualization of geodata allows for the analysis of large amount of data and assessment of their importance in the study of cartographic modeled issues.

\section{CARTOGRAPHIC GENERALIZATION AND SIMBOLIZATION}

A complex structure of geodata is necessary to graphically integrate and present in the cartographic presentation, so that it is adapted and based on the principles of cartographic generalization and cartographic design. The degree of generalization (geometric and semantic) affects the degree of integration of geodata that are graphically represented. Geodata are hierarchically presented in relation to their significance (topographic and thematic) in mapping. The information representation about relations between geoobjects is especially important in interactive maps, because it refers to levels of hierarchical connection regarding their purpose and method of use.

Cartographic generalization is a complex and demanding procedure in presenting the most important characteristics of geoenvironmental content. Factors that affect the generalization process are the following: - scale, - purpose and - map issues, - geographic characteristics of the environment, - original database, - applied key of the cartographic signs, - physical limitations of the media, - resolution, - graphic load - accuracy and 
legibility of the map. The generalization procedures are conditioned by the knowledge, skills and desires of the cartographic database users.

That is, taking into account the data structure and the way of visualization, the content generalization on the model can be the following:

- taxonomical - according to integration, defined class or content element;

- spatial - absolute (by coordinates) or relative (by objects vicinity);

- attributive - according to quantitative and qualitative characteristics of geoobjects;

- graphical - according to attributes of graphic entities with which the objects are designated in the model: type, colour, etc. [8].

The generalization and symbolization of the thematic map contents are key procedures for geo-visualization. Compliance and clarity of the graphic conception of the maps should reflect the unity of thoughtful expression and visual experience of the integrity of the mapped content. Solving the relationship between functionality and aesthetic design of the map content elements, the unity of the defined principles of cartographic generalization and design is achieved. Cartographic design as a form of expression encompasses the complexity of relations in a system of thematical, spatial, proportional, transparent, and practical significance [6]. As a graphic presentation of the map content structure, the cartographic design represents a significant factor in the communication process, on the cartographer $\rightarrow$ map $\rightarrow$ user relation.

The level of information is precisely defined by the map content structure and the method of its aesthetically integral presentation. The aesthetic mapping process, in order to emphasize the meaning as an analogue expression of the mapping object, is integrated and organized by the following four levels:

- qualitative level - contains associativity (implies unification by similarity) and selection (implies reduction according to differences, including classification);

- order level - determines the spatial and temporal order, as well as the order of sensitive (small - medium - large versus other) and value judgments (black - grey - white);

- quantitative level (metric level) - determines the mutual comparison of the size, number and quantity of the mapping phenomena parts within the entirety $(1 / 2,1 / 3$ or 9 times in relation to the other, etc.);

- organization level - contains an analogy to which graphic transcription is sought for [4].

Table 1. Indicators of the cartographic design quality in the communication process

\begin{tabular}{|cc||}
\hline \hline INDICATORS OF THE CARTOGRAPHIC DESIGN QUALITY \\
\hline \hline General & Individual \\
\hline & - visual expression; \\
- informational \\
expression & - solution originality; \\
& - style conformity; \\
& - forms unification; \\
& - actuality. \\
\hline \hline & - usability degree; \\
- solution & - purposefulnes; \\
rationality & - usefulness. \\
& \\
\hline \hline composition & - mutual harmony of \\
unity & individual elements; \\
(aesthetic expression) & graphical presentation; \\
\hline
\end{tabular}


The value of the cartographic design is reflected through its functionality in the process of visual cartographic communication. Providing quality complex information in a clear and comprehensible way and the possibility of objective analysis of the presented geodata to users is a basic task of design. Visual communication is accomplished by artistic and graphic expression, based on the requirements to be realized and integrated into a harmonious and systematized entirety, so that its quality corresponds to the purpose (Table 1).

Cartographic visualization must be consistent with the real way of organizing phenomena and processes in the physical world. Within this, it is necessary to answer the following questions:

- how to facilitate the use of maps in terms of faster understanding, research and increase of accuracy in measurement and calculation;

- how to present geographic information, in order to increase the efficiency of the analysis of the map content structure, which allows formulating the hypotheses, monitoring the phenomena over time;

- how to present diverse geographic information with the smallest visual deformations;

- which graphic scale variant should be chosen to maintain changes in qualitative and quantitative geographic indices, and

- what level of generalization for different user groups (different characteristics of observation) should be, and so on. [9].

The quality of integration of cartographic content stems from the quality synthesis of the three basic components: mathematical (geometric accuracy), geographical (geographical accuracy) and aesthetical components. Functionality in the use of a cartographic product depends on its: - transparency, - legibility, - accuracy, - obviousness, - authenticity (geographical, that is, factual compliance with reality), - aesthetics, - relevance of themes and purposes, - informatics, - modernity, - standardization, - updating and other. The aesthetical component is an indispensable part of the map, because it points to the integrity and functionality in compiling and using content, in relation to its purpose and method of practical use (Table 2). In other words, the aesthetical compliance of the map content affects the following: content clarity (understanding of information content) and graphic clarity (visual perception and forms recognition).

Table 2. Cartographic design requirements in the function of the cartographic products quality [12],[6]

\begin{tabular}{||cccccc||}
\hline \multicolumn{7}{|c|}{ CARTOGRAPHIC DESIGN } \\
\hline \hline $\begin{array}{c}\text { LEGIBILITY } \\
\text { size }\end{array}$ & TRANSPARENCY & ACCURACY & OBVIOUSNESS & AESTHETICS & REPRODUCTION \\
\hline \hline $\begin{array}{c}\text { graphic } \\
\text { density }\end{array}$ & simplicity & $\begin{array}{c}\text { geometric } \\
\text { accuracy of } \\
\text { position }\end{array}$ & symbolism & harmony & quality \\
\hline $\begin{array}{c}\text { distinguishing } \\
\text { known forms }\end{array}$ & $\begin{array}{c}\text { connectivity and } \\
\text { layering }\end{array}$ & $\begin{array}{c}\text { sign } \\
\text { accuracy }\end{array}$ & traditionality & beauty & economy \\
\hline
\end{tabular}

The map content is presented by a system of signs with defined meaning (syntactic, semantic, semiometric, sigmatic and pragmatic). The signs, by their shape, dimensions, orientation and colour, enable identification and thoughtfull expression of true reality. Visual transcription of reality takes place on a relation of meaning which is suggested by colour, shape, size, dynamic balance and typology of signs [6]. The transcription of reality is realized on the basis of the cartographic signs functions: 
- labeling (the sign refers to a particular phenomenon or process - represents it);

- referentiality ("standing" instead of something and reporting on meaning - bearer of meaning);

- structuring (the system of signs is linked by certain rules and levels);

- creativity (the ability to create a sign for any existing or conceived term);

- communicativeness (enables communication between people) [5];

- categorization (ability to designate categories - class of phenomena);

- meaningful connection (linking and combining signs point to existing and possible links and relationships of presented phenomena) and

- fixing, tracking and communicating various thoughtful contents and ideas.

The use of signs combined with colour increases the information properties of the map and achieves a better perception of the presented geographic content. Colours on maps help in differentiating content, transparency and representation symbolism. Of particular significance is the application of colours in the function of symbolism, as an expression of analogy with the phenomenon that is being mapped. This feature of the colour best comes to light in the following processes: - observation and identification, - analysis and synthesis, - generalization, - typization and classification, - comparison, - possibility for quick and clear visual perception of spatial-temporal links and relationships, - knowledge of characteristics, - essential differences and - tendencies of the presented phenomena.

Expression by signs and colour represents a form of designating the reality in the function of the context - recognition and distinction, structure of the presented content. By linking and combining signs and colours, it is possible to present the following: - position, spatial arrangement, and - phenomena arrangement, - type, - category, - structure, interconnections and conditionality of properties of related or different mapped phenomena, - connectivity, - intensity and - dynamics of the phenomenon, - meanings (thematical, spatial, temporal, rational), and so on.

Cartographic signs and colours as elements of the graphic form - symbolism of cartographic expression represent adequate means of representing qualitative and quantitative characteristics of the phenomena and processes of the geoenvironment in relation to their situational, positional and spatial connection. The signs allow the complicated geoobject structures to be reproduced with simple graphic forms or their combinations [3]. The method in which specific cartographic content is presented is a complex process and requires integrated geodata structure-based processing of the issues.

\section{CONCLUSION}

The need for transforming geoenvironmental databases into a cartographic form is present in many areas of human activity. The method in which specific cartographic content is presented is a complex process and requires an integrated processing of the geodata structure of the defined issues. The conversion of data of the spatial databases into the cartographically integrated geodata structure requires that they are: - accurate (geometrically and attributively authentic with a real, clear and complete level of distinction), - current, - complex and - functional (in order to transform into a state of usefulness ), - reliable (derived from an adequate source), - spatially and - temporally safe for integration and use.

Contextually and graphically, thematically defined and standardized geodata infrastructure enables its quality processing and visualization. Digital technology enables the following: - quick and efficient representation of the map content; - fast access to data, as a crucial condition for decision making and communication; - interactivity of data and 
their visualization (dynamic and intelligent data linking); - graphical interaction with end users; - great possibilities for thematic mapping; - comparison of several indicators; adjusting the data representation in relation to the purpose and circle of users; - interactive selection; - creating tables, charts, etc.; - facilitated understanding by interaction, comparing and visualizing complex reality; - discovering the hidden meaning of data; linking with real-time strategic data; - monitoring of data changes and - real-time updates, etc.

A complex structure of geodata is necessary to be graphically integrated and presented in the cartographic representation, so that it is adapted and based on the principles of cartographic generalization and cartographic design.

Integration of geodata (location and attribute) rationalizes and increases user-driven analytic potential. The primary data of the geoenvironment from the database are integrated and transformed by geo-visualization into cartographic environment, so that interpretation and analysis can manage modeled data.

\section{LITERATURE}

[1] Andrienko, G. \& Andrienko, N. Interactive maps for visual data exploration. International Journal of Geographical Information Science, 13(4), pp. 355-374, 1999.

[2] Andrienko, N. \& Andrienko, G. A visual analytics framework for spatio-temporal analysis and modelling. Data Mining and Knowledge Discovery, 27(1), pp. 55-83, 2012. doi:10.1007/s10618-012-0285-7

[3] Arnberger, E. Handbuch der Thematischen Kartographie. Wien: Franz Deuticke, 1966.

[4] Bertin, J. Semiologie graphique, diagrammes, reseauks, cartographie. Paris: Gauthier-Villars, 1967.

[5] Gleitman, H. \& Fridlund, A. J. \& Reisberg, D. Psychology. New York: Nort and Co, 1999.

[6] Јовановић, Ј. Картографски дизајн као форма изражавања. Зборник радова Први конгрес српских географа. књ. 3. Београд: СГД, ГИ ”Јован Цвијић” САНУ и Географски факултет Универзитета у Београду, Нови Сад: Департман за географију, туризам и хотелијарство ПМФ, Србија, стр. 1103-1109, 2007.

[7] Јовановић, Ј. Картографска комуникација у функцији информационе и едукативне комуникације. Зборник радова ГИ "Јован Цвијић” САНУ, књ. 57, Београд: ГИ "Јован Цвијић” САНУ, стр. 451-458, 2007.

[8] Јовановић, М. Ј. Тематска картографија, практикум. Београд: Универзитет у Београду Географски факултет, 2017.

[9] Robinson, A. H. \& Morrison, J. L. \& Muehrcke, P. C. \& Kimerling, A. J. \& Guptill, S. C. Elements of Cartography. $6^{\text {th }}$ ed.New York, N.Y: John Wiley\&Sons, 1995.

[10] Robinson, A. C \& Demsar, U. \& Moore, A. B. \& Buckley, A. \& Jiang, B. \& Field, Kraak, M-J. \& Camboim, S. P. \& Sluter, C. R. Geospatial big data and cartography: research challenges and opportunities for making maps that matter. International Journal of Cartography, 3 (Supl. 1), pp. 32-6, 2017. DOI: 10.1080/23729333.2016.1278151

[11] Roth, R. E. Interactive maps: What we know and what we need to know. The Journal of Spatial Information Science, 6, pp. 59-115, 2013.

[12] Frangeš, S. Zahtjevi postavljeni suvremenoj kartografskoj vizuelizaciji. Kartografija i geoinformacije, poseban broj, Zagreb: HKD, str. 55-73, 2007.

[13] URL-1: http://kartoweb.itc.nl/icavis/index.html (ICA Commission on Visualization)

[14] URL-2: https://studopedia.org/8-219217.html 